\title{
Disseminated histoplasma and CMV infection presenting as subacute intestinal obstruction in an immunocompromised patient
}

\author{
Lokesh Shahani \\ Department of Internal Medicine, Southern Illinois University School of Medicine, Springfield, Illinois, United States
}

Correspondence toDr Lokesh Shahani, lokesh83@hotmail.com

\begin{abstract}
Summary
Histoplasma in patients with impaired cellular immunity can disseminate to various organs and is known as progressive disseminated histoplasmosis. Similarly cytomegalovirus (CMV) is the most common opportunistic pathogen in an immunocompromised host. The authors report an older male with symptoms and radiological evidence of subacute intestinal obstruction. The patient had concerns for compromised immune system as he was on chronic prednisone and methotrexate therapy. Follow-up colonoscopy revealed a stricture in the proximal ascending colon. Biopsy of the stricture revealed ulcer with granulomatous inflammation including well-formed granulomas and an infiltrate of histiocytes within the lamina propria. Special stains on the specimen showed fungal structures consistent with Histoplasma capsulatum. Immunochemistry showed presence of CMV in the tissue. The patient had good response to antimicrobial therapy and did not have progression of intestinal obstruction. This case highlights the need to consider infectious pathology in immunocompromised patients presenting with obstructive symptoms.
\end{abstract}

\section{BACKGROUND}

The number of immunocompromised patients continues to grow each day with the growing number of immunosuppresive drugs being used for the treatment of various rheumatologic conditions, organ transplantation and malignancies. The lymphoid tissue of the gastrointestinal (GI) tract and the associated $\mathrm{T}$ lymphocytes play an important role in defense against various pathogens. The immunosupression dysregulates the function of the $T$ helper cells leading the GI tract to be susceptible to various opportunistic infections.

\section{CASE PRESENTATION}

We report a 77-year-old white male presenting to an outlying endoplasmic reticulum (ER) with a 1 day history of right upper quadrant pain. Pain was described as being present in the right upper quadrant, episodic in nature lasting for $15 \mathrm{~min}$ and then resolving on its own. The patient had not had a bowel movement for the past 5 days prior to the presentation, however was passing flatus. He denied any nausea, vomiting or any abdominal distension. A computerised axial tomography (CAT) scan was done in the peripheral ER which showed cecal dilatation with concerns for a cecal narrowing or twisting. Hence the patient was transferred to our tertiary hospital for further care.

The patient had a medical history significant for rheumatoid arthritis, diabetes mellitus, ischemic cardiomyopathy with an ejection fraction of $45 \%$ and atrial fibrillation. He was on methotrexate $15 \mathrm{mg}$ a week and prednisone $5 \mathrm{mg}$ daily for his rheumatoid arthritis. The patient was a resident of Southern Illinois and denied any current alcohol, smoking or intravenous drug use. He admitted to feeding birds on a regular basis
He was haemodynamically stable on admission. His physical examination revealed tenderness in the right upper abdominal quadrant. Bowel sounds were present and tympanic note on percussion was appreciated in all quadrants. No peritoneal signs were appreciated on physical examination.

\section{INVESTIGATIONS}

The patient's initial labs were within normal limits. The patient had a gastrograffin enema which revealed large amount of stool in the large intestine and luminal irregularity of the sigmoid colon.

The patient had a follow-up colonoscopy which revealed an ulcerating lesion causing a stricture in the proximal

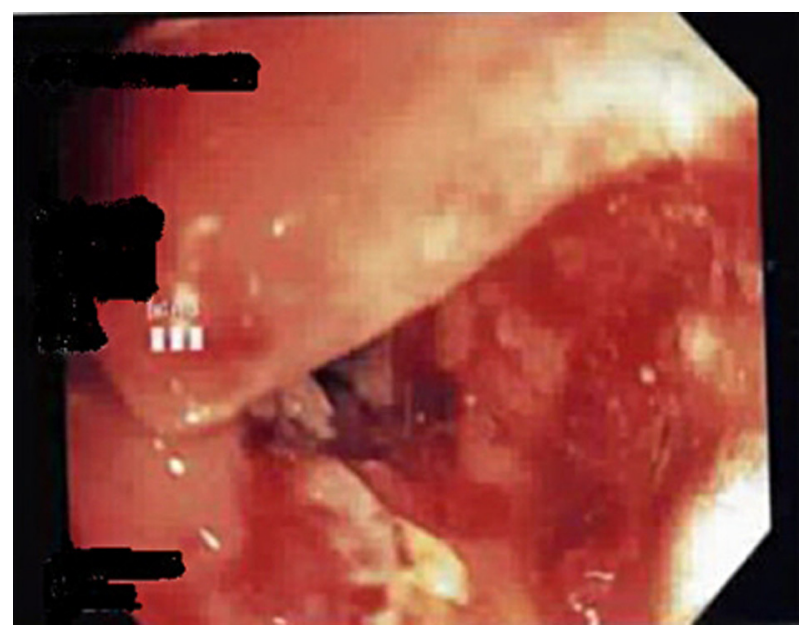

Figure 1 Colonoscopy showing ulcerating lesion in the proximal ascending colon. 
ascending colon (figure 1). A biopsy of the same was done which revealed granulomatous inflammation (figure 2) including well-formed granulomas as well as an infiltrate of histiocytes within the lamina propria. Grocott's methenamine silver and periodic acid-Schiff stains on the specimen showed fungal structures, consistent with Histoplasma capsulatum (figure 3). Immunochemistry performed on the specimen showed presence of cytomegalovirus (CMV) in the tissue (figure 4).

Histoplasma serum antigen was positive $(1.23 \mathrm{ng} / \mathrm{ml})$ and histoplasma yeast antibody was positive (1: 64). The histoplasma urine antigen was negative. Two thousand five hundred copies/ml of CMV DNA were detected and CMV IgG was positive. HIV ELISA was negative for the patient; however, CD4 count was not checked for the patient.

\section{TREATMENT}

The patient was started on liposomal amphotericin B 5 $\mathrm{mg} / \mathrm{kg} /$ day dose for 2 weeks and later to be switched to oral itraconazole $200 \mathrm{mg}$ twice a day to be taken for a year. The CMV infection was treated with oral valganciclovir $450 \mathrm{mg}$ twice a day for 6 weeks (adjusted for patient's renal function).

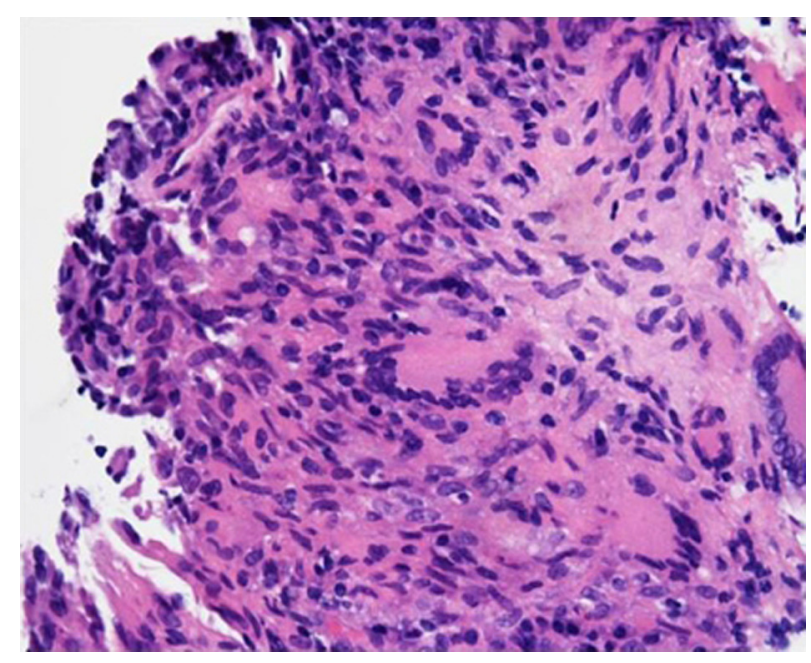

Figure 2 Granulomatous inflammation on biopsy of the lesion.

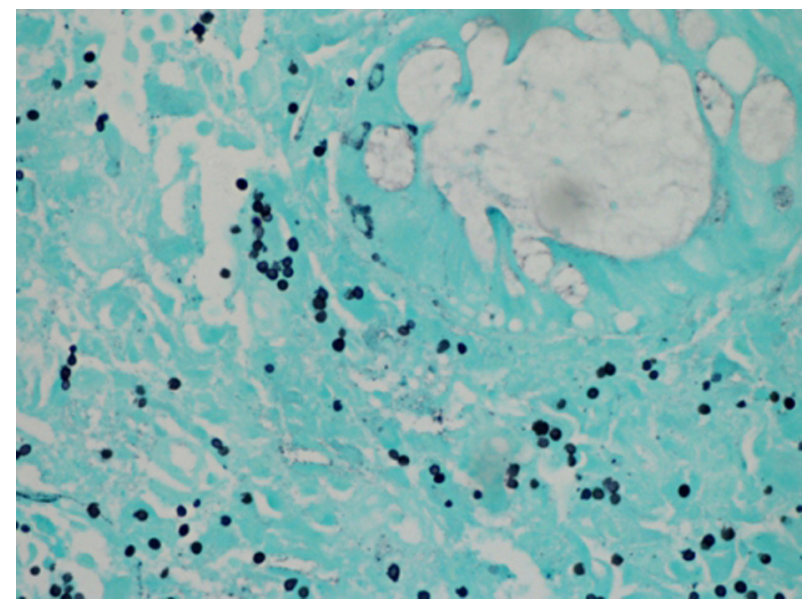

Figure 3 Grocott's methenamine silver stain for Histoplasma capsulatum.
Considering the patient's multiple medical co morbidities and the high risk surgical procedure it was decided to continue to follow the patient serially with radiologic and endoscopic imaging and monitor for worsening of intestinal obstruction. Recurrence of GI histoplasmosis is common and hence the patient is regularly followed at the infectious disease clinic.

\section{OUTCOME AND FOLLOW-UP}

Prior to his dismissal, the patient underwent a CAT scan of the abdomen and pelvis, which showed a focal abnormal

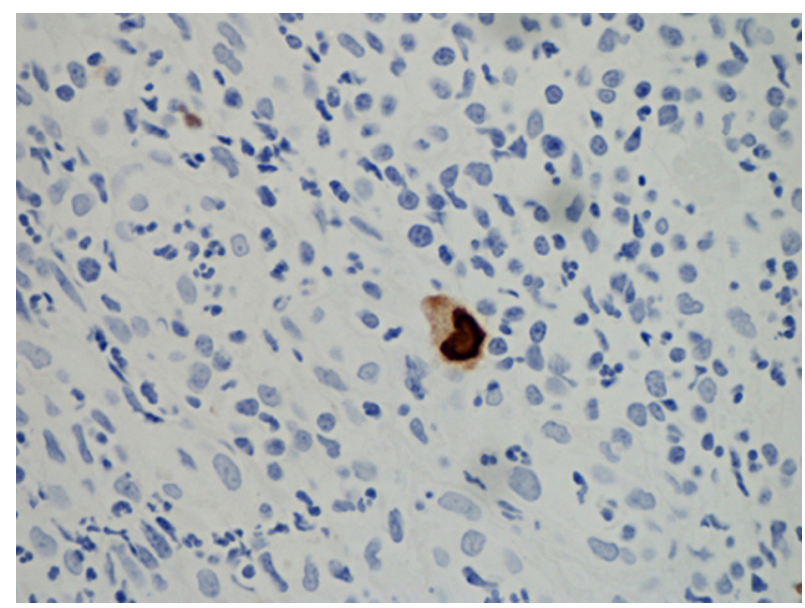

Figure 4 Immunohistochemistry for cytomegalovirus.

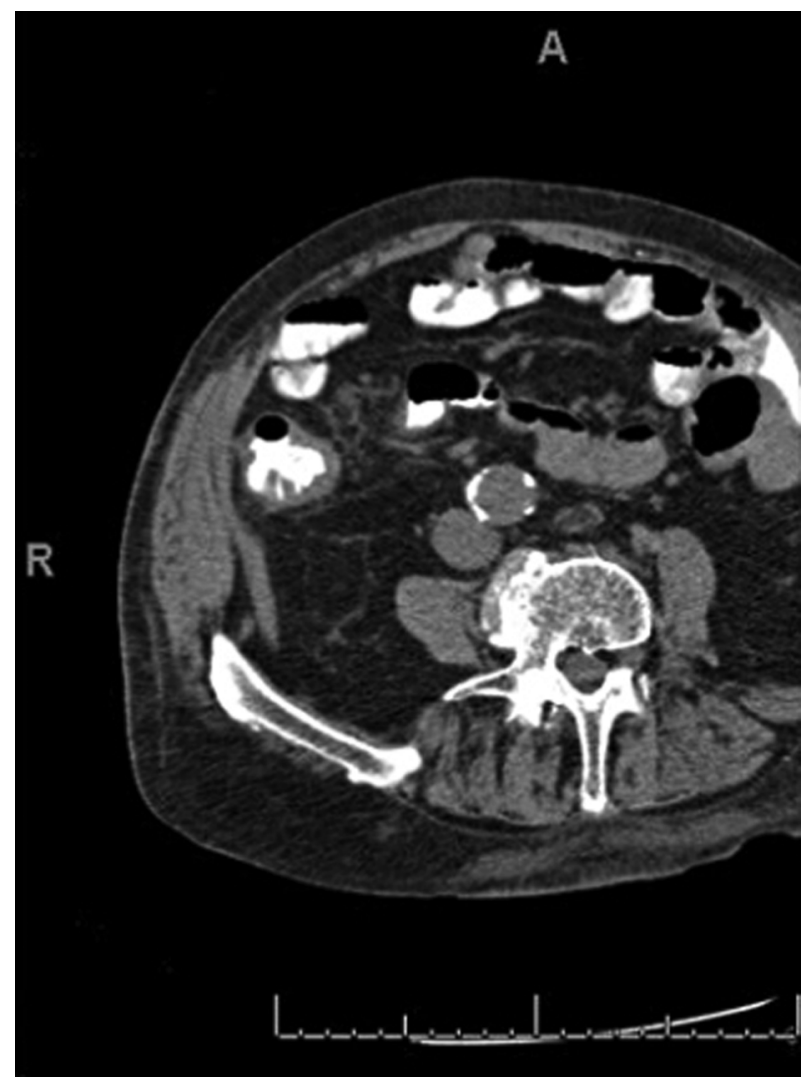

Figure 5 CT abdomen showing thickening of a focal abnormal, thickening and luminal narrowing of the cecum and terminal ileum. 
thickening and luminal narrowing of the cecum and terminal ileum, although there was no evidence of any obstruction seen (figure 5).

The patient presented a month later with gradually worsening lower extremity oedema, dyspnoea on exertion, orthopena and paroxysmal nocturnal dyspnoea. With concerns for itraconazole worsening the congestive heart failure the patient was switched to posaconazole $400 \mathrm{mg}$ twice a day.

The patient has been followed at the outpatient clinic and has been doing well and has not had any recurrent symptoms suggestive of bowel obstruction.

\section{DISCUSSION}

Immunosupressive drugs remain the mainstay in the treatment of rheumatoid arthritis. Low to moderate daily dose of glucocorticoids has been associated with a reduction in the number of $\mathrm{T}$ lymphocytes in the circulation. CD4positive cells are more affected than CD8-positive $\mathrm{T}$ cells at this dose. ${ }^{1}$

Histoplasmosis is a granulomatous disease caused by the intracellular dimorphic fungus $H$ capsulatum. It is endemic to areas such as Ohio, Missouri and Mississippi River valleys in North America and soil enriched with bird or bat droppings promote the growth and sporulation of Histoplasma. In immunocompetent individuals, the infections are usually asymptomatic and self limited. However in patients with impaired cellular immunity, the infection can disseminate to various organs and is known as progressive disseminated histoplasmosis (PDH). The GI tract is involved in up to $90 \%$ cases of $\mathrm{PDH}$, however, specific GI features are uncommon. ${ }^{2-5}$ Terminal ileum and cecum are most frequently involved sites ${ }^{3}$ and endoscopic findings include plaques, polyps, mucosal oedema, ulcerations, strictures and masses. ${ }^{2} 5$

CMV infection has an estimated prevalence of 60 to $70 \%$ in the US population ${ }^{6}$ and is the most common opportunistic pathogen in an immunocompromised host causing severe morbidity and mortality. ${ }^{7} \mathrm{CMV}$ infection has a chronic latent state during which the virus remains present within host cells, but viral proliferation is prevented by host cell-mediated immunity. Failure of immune containment may lead to reactivation with viral proliferation and severe systemic illness. Colitis is a frequent manifestation of this acute systemic illness.

We report a patient with compromised immune system presenting with subacute bowel obstruction. Colonoscopy revealed a stricture in the ascending colon and further biopsy revealed a coinfection with histoplasma and CMV.
The patient was a high risk candidate due to his medical comorbidities and hence was treated medically. With appropriate therapy for his infection the patient responded well and did not have progression of his intestinal obstruction. This case highlights the need to consider infectious pathology in immunocompromised patients presenting with obstructive symptoms.

\section{Learning points}

- Histoplasmosis is a granulomatous disease caused by the intracellular dimorphic fungus $H$ capsulatum. In immunocompetent individuals. the infections are usually asymptomatic and self limited. However, in patients with impaired cellular immunity the infection can disseminate to various organs and is known as progressive disseminated histoplasmosis.

- CMV infection has an estimated prevalence of 60 to $70 \%$ in the US population and is the most common opportunistic pathogen in an immunocompromised host causing severe morbidity and mortality.

- The lymphoid tissue of the GI tract and the associated T lymphocytes play an important role in defence against various pathogens. The immunosupression dysregulates the function of the T helper cells leading the $\mathrm{Gl}$ tract to be susceptible to various opportunistic infections.

Competing interests None.

Patient consent Obtained.

\section{REFERENCES}

1. Haynes BF, Fauci AS. The differential effect of in vivo hydrocortisone on the kinetics of subpopulations of human peripheral blood thymus-derived lymphocytes. J Clin Invest 1978;61:703-7.

2. Lamps LW, Molina CP, West AB, et al. The pathologic spectrum of gastrointestinal and hepatic histoplasmosis. Am J Clin Pathol 2000;113:64-72

3. Cappell MS, Mandell W, Grimes MM, et al. Gastrointestinal histoplasmosis. Dig Dis Sci 1988;33:353-60.

4. Mullick SS, Mody DR, Schwartz MR. Cytology of gastrointestinal histoplasmosis. A report of two cases with differential diagnosis and diagnostic pitfalls. Acta Cytol 1996;40:989-94.

5. Hertan H, Nair S, Arguello P. Progressive gastrointestinal histoplasmosis leading to colonic obstruction two years after initial presentation. Am J Gastroenterol 2001;96:221-2.

6. Zhang LJ, Hanff P, Rutherford C, et al. Detection of human cytomegalovirus DNA, RNA, and antibody in normal donor blood. J Infect Dis 1995:171:1002-6.

7. Patel R, Snydman DR, Rubin RH, et al. Cytomegalovirus prophylaxis in solid organ transplant recipients. Transplantation 1996;61:1279-89. 


\section{BMJ Case Reports}

This pdf has been created automatically from the final edited text and images.

Copyright 2012 BMJ Publishing Group. All rights reserved. For permission to reuse any of this content visit http://group.bmj.com/group/rights-licensing/permissions.

BMJ Case Report Fellows may re-use this article for personal use and teaching without any further permission.

Please cite this article as follows (you will need to access the article online to obtain the date of publication).

Shahani L. Disseminated histoplasma and CMV infection presenting as subacute intestinal obstruction in an immunocompromised patient. BMJ Case Reports 2012;10.1136/bcr.08.2011.4732, Published XXX

Become a Fellow of BMJ Case Reports today and you can:

- Submit as many cases as you like

- Enjoy fast sympathetic peer review and rapid publication of accepted articles

- Access all the published articles

Re-use any of the published material for personal use and teaching without further permission

For information on Institutional Fellowships contact consortiasales@bmjgroup.com

Visit casereports.bmj.com for more articles like this and to become a Fellow

Keep up to date with all published cases by signing up for an alert (all we need is your email address) http://casereports.bmj.com/cgi/alerts/etoc 